\section{CHILD DEVELOPMENT AND DISABILITY}

\section{G174 THE CHANGING INCIDENCE OF AUTISTIC SPECTRUM DISORDERS}

Powell $\mathrm{JE}^{1}$, Edwards $\mathrm{A}^{2}$, Edwards $\mathrm{M}^{2}$, Pandit $\mathrm{S}^{2}$, Sungum-Paliwal $\mathrm{SR}^{3}$, Whitehouse $\mathrm{W}^{2}$ Departments of ${ }^{1}$ Public Health \& Epidemiology, University of Birmingham and ${ }^{2}$ Paediatric Neurology, ${ }^{3}$ Child \& Adolescent Psychiatry, Birmingham Children's Hospital NHS Trust, Birmingham B4 6NH

Aims: The incidence and prevalence of autistic spectrum disorders (ASDs) seems to be rising. We therefore measured incidence and prevalence in preschool children, in two discrete, geographically defined populations.

Methods: Children diagnosed with ASD aged 1 year to 4 years 11 months were ascertained from the Child Development Centres serving South Birmingham (population aged 1-4 years: 25,000) and Tamworth (population aged 1-4 years: 4,000), and a regional specialist psychiatry clinic, resident and diagnosed from 1.1.91 to 31.12.96. DSM-IIIR, DSM-IV and ICD10 categories were used.

Results: The age-specific incidence for ASD was the same in both populations despite differences in social deprivation and the proportion of ethnic minorities. It rose from 3.5/10,000/year in 1991-92 to $13.1 / 10,000 /$ year in 1995-96. The incidence of the more narrowly defined "Childhood Autism" rose less steeply: from 2.7 to $4.3 / 10,000 /$ year. The incidence of ASDs increased on average by $37 \%$ per year. The annual period prevalence for $199634.0 / 10,000$ and the cumulative incidence to 5th birthday for the 1991 birth cohort was $42 / 10,000$.

Conclusions: The incidence of diagnosed ASDs is increasing. This may be due to a biological increase or to increased willingness by professionals to use these diagnoses, especially for children with ASDs other than narrowly defined "Childhood Autism", or a combination of both.

\section{G175 FURTHER EVIDENCE FOR THE ROLE OF MATERNALLY INHERITED CHROMOSOME 15Q11 DUPLICATION IN AUTISM: A FAMILY STUDY} L.Greenhalgh, R.Howell, M.Bredow, R.Newbury-Ecob Department of Clinical
Genetics Bristol Children's Hospital

Previous studies have implicated maternally inherited interstitial duplications of chromosome15q11 in the aetiology of autism. We investigated this in a family, in whom, a duplication of chromosome15q11 was segregating.

Standard karyoptye analysis of twin girls with autism and developmental delay showed an interstitial duplication of chromosome 15q11.q22. FISH analysis using the SNRPN gene probe confirmed duplication of this gene locus.

Results of other family members karyotypes showed that the mother of the twins and their maternal grandfather had the interstitial duplication of chromosome 15 q11, neither of whom showed any clinical signs of autism.

These results confirm previous observations that maternally inherited chromosome $15 q 11$ duplications are associated with autism. Paternal inheritance of the duplication has no phenotypic effect. The duplicated region is known to be imprinted, being the same as the critical region for Prader Willi syndrome and Angleman's syndrome. Prader willi syndrome and Angleman's syndrome result form deletion or disomy of the maternal or paternal chromosome 15.

This family presented an opportunity to study the role of maternally duplicated chromosome $15 q 11$ in autism and will aid the search for candidate genes.

\section{G176 THYROID DYSFUNCTION IN DOWN'S SYNDROME; A} COMPARATIVE STUDY OF TWO SCREENING METHODS

Varadkar S, *Reynolds AP, Lessing D Hounslow \& Spelthorne Community \& Mental Health NHS Trust, West Middlesex University Hospital, Isleworth ${ }^{*}$ Great Ormond Street Hospital for Children NHS Trust and Institute of Child Health

Introduction: Current practice is to screen children with Down's syndrome (DS) for thyroid dysfunction using venous blood (VB). Capillary blood spot (CBS) on filter paper has been proposed as an alternative although there are no published data comparing the two methods in this population. The aim of this study was to compare VB sampling with CBS as a screening method for thyroid dysfunction, in a community based sample of children with DS.

Methods: All children with DS on the special needs register of Hounslow borough were identified. Venous blood was taken for Thyroid Stimulating Hormone (TSH), and assayed by standard methods. On the same occasion capillary blood by finger or toe prick was spotted onto filter paper and TSH levels measured by coated tube radiometric assay at a reference laboratory. Results of the two tests were compared.

Results: Fifty-eight children were identified, 6 declined consent, 52 children participated, range $1.4-18.8$ yrs, mean 7.3 yrs. Comparison of VB-TSH and CBS-TSH revealed a good correlation, Pearson correlation coefficient $=0.76$. Seven subjects (13\%) had a VB-TSH $>5.5 \mathrm{mU} / \mathrm{l}$, upper limit of reference range for VB-TSH. The range of CBS-TSH in these 7 subjects was $3.0-7.0 \mathrm{mU} /$, mean $4.4 \pm 1.4$. None of the 52 subjects had a capillary blood-spot TSH 10 $\mathrm{mU} / \mathrm{l}$, the cut off for neonatal screening programmes.

Conclusions: Capillary blood-spot TSH is a useful and simpler alternative to venous blood sampling as a screening test for thyroid dysfunction in children with Down's syndrome. These results suggest that the use of the neonatal CBS-TSH cut-off value of $\geq 10 \mathrm{mU} / \mathrm{l}$ is inappropriate in older children, failing to detect subclinical hypothyroidism. Larger studies are required to establish the appropriate reference range.

\section{G177 IDENTIFICATION OF NEONATES AT RISK OF DEVELOPING FEEDING PROBLEMS IN INFANCY}

Hawdon JM, Beauregard N, Slattery J, Kennedy G Neonatal Unit, University College London Hospitals

Despite increased survival of sick and preterm neonates, long term problems such as feeding difficulties may contribute to failure to thrive and psychosocial distress.

In a prospective study, 35 neonates who had been admitted for intensive care underwent feeding assessments at term and were categorised as disorganised, dysfunctional or normal feeders (Palmer et al, 1993). Follow up at 6 and 12 months was by parent completed feeding questionnaire.

Median (range) gestation at birth was 32 (23-42) weeks. 14 (40\%) infants had disorganised or dysfunctional feeding patterns. Compared to normal feeders, these babies had longer duration of respiratory support $(p=0.031)$, were more likely to have neurological disorders $(p<0.001)$, and delayed enteral $(p=0.008)$ and oral $(p=0.001)$ feeding. At 6 months age, compared to neonates with normal initial feeding assessments, neonates with disorganised or dysfunctional feeding were 6 times more likely to vomit $(p=0.005)$ and 3 times more likely to cough when offered solid food $(p=0.010)$. Significant differences were also found at 12 months age in terms of tolerating lumpy food $(p=0.015)$, coughing during feeds $(p=0.016)$ and poor enjoyment of mealtimes $(p=0.001)$.

It is possible to predict, from clinical history and neonatal feeding assessment, infants at risk of serious feeding problems. Predisposing features should be identified and preventive strategies evaluated.

Palmer MM et al. Neonatal oral-motor assessment scale: a reliability study. $J$ Perinatol 1993;8:28-34

\section{G178 PERINATAL RISK FACTORS FOR ADVERSE OPHTHALMIC OUTCOME IN CHILDREN BORN <1701G AT THE AGE OF 10-12 YEARS}

O'Connor AR, Stephenson TJ, Johnson $A,{ }^{1}$ Tobin $\mathrm{M}^{2}, \mathrm{Ng} \mathrm{Y}$, Stevenson J, Fielder $\mathrm{AR}^{3}$ Academic Division of Child Health, Nottingham University;

${ }^{1}$ NPEU, Oxford Univeristy ${ }^{2}$ Birmingham University; ${ }^{3}$ Imperial College of Science Technology and Medicine

Aim: To identify perinatal factors predictive of adverse ophthalmic outcome in a cohort of low birthweight children.

Methods: Between 1985 and 1987, 572 infants weighing less than 1701g at birth had serial eye examinations between the ages of 3 and 12 weeks. The cohort was traced at age 10-12 years and examined for: visual acuity, contrast sensitivity, colour vision, eye movements and refractive error. A control group of 169 eleven year-old children who were born at term was also examined. The data from the perinatal period included severity of retinopathy of prematurity (ROP). An adverse ophthalmic outcome (AOO) was defined as visual acuity below the accepted norm (6/6), or the presence of strabismus, myopia, colour vision defect or visual field defect.

Results: 530 of the cohort were traced and 293 consented to examination. There was a relationship between adverse outcome and stage of ROP. Those with no or mild ROP had a higher rate of adverse outcome compared with controls $\left(p<0.001, \chi^{2}\right)$.

\begin{tabular}{lllllll}
\hline & no & stage 1 & stage 2 & stage 3/4 & $\begin{array}{l}\text { All children } \\
<1701 \mathrm{~g}\end{array}$ & controls \\
\hline ROP & & & & $65 \%$ & \\
\hline AOO & $48.9 \%$ & $50 \%$ & $60 \%$ & $85.7 \%$ & $52.6 \%$ & $19.5 \%$ \\
& $(n=69)$ & $(n=49)$ & $(n=24)$ & $(n=12)$ & $(n=154)$ & $(n=33)$ \\
\hline
\end{tabular}

Multivariate modelling showed independent statistical associations between perinatal factors, including birthweight, gestational age, duration of ventilation, the number of intubations and ophthalmic outcome $(p<0.05)$. However the predictive power of these variables is poor (maximum adjusted $R^{2}=0.091$ ).

Conclusions: Ophthalmic morbidity is associated with severe ROP and birthweight $<1701 \mathrm{~g}$ per se. Despite statistical associations with measures of ophthalmic morbidity, neonatal variables are poor predictors of ophthalmic outcome.

\section{G179 CEREBRAL PALSY AND SOCIOECONOMIC STATUS: A} RETROSPECTIVE COHORT STUDY

${ }^{1}$ Sundrum R, ${ }^{2}$ Logan S, ${ }^{3}$ Spencer NJ, ${ }^{4}$ Wallace A ${ }^{1}$ Lecturer in Community Child Health, St Bartholomew's and the Royal London School of Medicine;

${ }^{2}$ Senior Lecturer in Paediatric Epidemiology, Institute of Child Health; 
${ }^{3}$ Professor of Community Child Health, Warwick University, ${ }^{4}$ Community Paediatrician, Chichester

Objective: To study the relationship between cerebral palsy and socio-economic status.

Setting: West Sussex.

Study design: Retrospective cohort study based on routine register of births and of children with special needs born between 1.1.80 and 31.12.96.

Main outcomes: Cerebral palsy; sub-type of cerebral palsy; severity of cerebral palsy.

Methods: Children with a diagnosis of cerebral palsy at the age of 2 years were identified from the special needs register of the West Sussex Child Health Computer. Postcode (converted to enumeration district (ED)), Registrar General's social class (RGSC), birthweight and gestational age were extracted for all children. Type and severity of cerebral palsy was extracted from the special needs register. Townsend Deprivation Index (TDI) was calculated for each ED based on census data and EDs ranked into deciles. Prevalence rates for cerebral palsy were calculated by ED decile, RGSC, birthweight group and gestational age.

Results: There was a strong linear association between risk of cerebral palsy and socio-economic status (SES) measured by ED decile (Chi square for linear trend $=4.56, p=0.03$ ). $31 \%$ of cases of cerebral palsy were statistically "attributable" to inequality in SES. The association between SES and risk of cerebral palsy persisted in a logistic regression model which included birthweight and gestational age. No statistically significant relationship was found between the risk of cerebral palsy and RGSC.

Conclusions: There is a strong association between socio-economic status and the risk of cerebral palsy which is only partly accounted for by the known social gradients in birthweight and gestational age. 